\title{
POLÍTICAS PÚBLICAS PARA AGRICULTURA FAMILIAR: UM ESTUDO DE CASO DOS IMPACTOS DO PRONAF NO ASSENTAMENTO VINGT ROSADO - MOSSORÓ/RN
}

\author{
P. A. M. DIAS E E. A. TACCONI NETO \\ Instituto Federal de Educação, Ciência e Tecnologia do Rio Grande do Norte \\ patrícia_araujomd@hotmail.com \\ ernesto.tacconi@ifrn.edu.br
}

Artigo submetido em 25/07/2018 e aceito em 31/07/2018

DOI: 10.15628 /empirica.2017.7538

\section{RESUMO}

A agricultura familiar passou por longos períodos de esquecimento no cenário agrícola brasileiro, a falta de políticas públicas direcionadas para essa área, contribuiu para problemas sociais diversos. O homem passou a migrar para a área urbana, pois sem investimentos sua permanência passou a ser insustentável, ficando difícil competir com grandes produtores agrícolas. A agricultura familiar tem como base os membros da família, que exercem funções variadas. A criação de políticas públicas para a agricultura familiar permitiu a continuação e subsistência destes no campo, sendo necessário que o Estado desenvolvesse políticas públicas de investimentos que permitisse o desenvolvimento da agricultura familiar, portanto o objetivo deste trabalho é analisar os impactos da aplicação do PRONAF no assentamento Vingt Rosado Mossoró/RN na percepção dos agricultores familiares. Na oportunidade foram entrevistados 30 agricultores familiares do assentamento rural. 0 estudo de caso se caracterizou como uma pesquisa descritiva, e também qualitativa e quantitativa. 0 instrumento utilizado foi um formulário com perguntas abertas e fechadas. Os resultados revelaram que as principais linhas do PRONAF utilizados pelas famílias assentadas são do PRONAF A, A/C e B. Através da análise do referencial teórico pesquisado verificou se que as famílias encontram dificuldades em dar continuidades nos programas, devido a vários fatores como, de inadimplência junto aos bancos, assistência técnica insuficiente e o próprio convívio em comunidade. Mesmo com as diversidades encontradas chegou se a conclusão que os impactos do PRONAF foram positivos inferindo na qualidade vida dos agricultores, com relação à oportunidade de emprego e moradia.

PALAVRAS-CHAVE: Políticas públicas, agricultura familiar, PRONAF, assentamento rural. 


\section{PUBLIC POLICIES FOR FAMILY AGRICULTURE: A CASE STUDY OF PRONAF IMPACTS IN VINGT ROSADO - MOSSORÓ/RN.}

\section{ABSTRACT}

Family farming went through long periods of forgetfulness in the Brazilian agricultural scene, the lack of public policies directed to this area, contributed to diverse social problems. The man began to migrate to the urban area, because without investments his permanence became unsustainable, making it difficult to compete with large agricultural producers. Family farming is based on family members, who perform varied functions. The creation of public policies for family agriculture allowed the continuation and subsistence of these in the field, it being necessary for the State to develop public investment policies that would allow the development of family agriculture, so the objective of this work is to analyze the impacts of the application of PRONAF in the Vingt Rosado Mossoró / RN settlement in the perception of family farmers. In the opportunity were interviewed 30 family farmers of the rural settlement. The case study was characterized as a descriptive, qualitative and quantitative research. The instrument used was a form with open and closed questions. The results showed that the main PRONAF lines used by the settled families are PRONAF A, A / C and B. Through the analysis of the theoretical framework researched, it was noticed that the impacts of PRONAF were positive in the quality of life of the farmers, with relation opportunity for employment and housing. It was also found that families find it difficult to give continuity to the programs, due to several factors, such as the difficulties of defaulting on banks, insufficient technical assistance and community living.

KEYWORDS: Public policies, family farming, PRONAF, rural settlement.

\section{INTRODUÇÃO}

A agricultura familiar ao longo do tempo vem sofrendo grandes rompimentos estruturais, devido a diversos fatores, resultado de uma estrutura agrícola fragilizada, principalmente em relação a pequenos agricultores. Diversos pontos atuam de forma negativa que contribui para atrasos na agricultura familiar, fatores como: pouca abrangência das políticas públicas até meados de 2002 (que por determinado período não assistia parte dessa classe trabalhadora rural), fatores econômicos, sociais, o avanço tecnológico e outros.

Essas condições levaram o homem do campo a buscar emprego na área urbana, houve uma desestabilização e abandono da zona rural, gerando um índice maior de desemprego. Sem um devido auxilio nessa área ou criação e aplicação dessas políticas públicas, a permanência do agricultor no campo se torna difícil, haja vista que para o pequeno agricultor sua subsistência no campo, devido aos diversos fatores, fica cada vez mais dependente da intervenção do Estado.

Segundo Carneiro (2007, p. 1): 


\section{ISSN - 2447-178X}

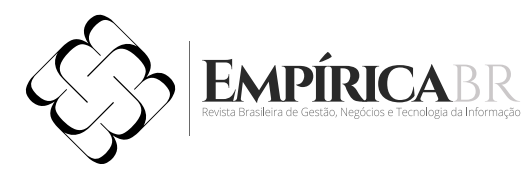

Há décadas relegada a segundo plano e até mesmo esquecida pelo Estado, a agricultura familiar e a sua base fundiária -a pequena propriedade- têm sobrevivido em meio à competição de condições e recursos orientados para favorecer a grande produção e a grande propriedade - setores privilegiados no processo de modernização da agricultura brasileira.

O Estado assim desenvolve um papel exato para a sobrevivência dos pequenos agricultores, fato esse que não aconteceu por um longo período. Os produtores do campo tiveram um apoio maior com a criação do Sistema Nacional de Crédito Rural (SNCR) a partir da institucionalização do crédito rural com a Lei $n^{\circ} 4.829$ em novembro de 1965 que foi regulamentada pelo decreto $n^{\circ} 58.380$ de 10 de maio de 1966. Só que infelizmente as reformas e a criação das políticas na área agrícola, favoreceram apenas os grandes produtores causando um colapso e quebra de subsistência do pequeno agricultor com o campo, pois não havia como concorrer com grandes produtores que possuíam acesso a tecnologias mais avançadas.

De acordo com Guanziroli, Buainain e Di Sabbato (2012, p. 352):

Deve-se lembrar que ser agricultor familiar não tem nenhuma conotação de superioridade em relação aos não familiares, trata-se apenas de diferenciar uma categoria que baseia sua produção no uso preferencial da mão de obra familiar e que exerce a gestão do empreendimento de forma direta, presencial, por meio de algum dos familiares envolvidos na produção.

Não tendo bases mais desenvolvidas e políticas públicas voltadas para os pequenos agricultores, o êxodo rural acabou sendo inevitável. Para garantir essa permanência do homem no campo, foi preciso voltar os olhos de maneira mais apurada para a atual situação, a criação do Programa Nacional de Fortalecimento da Agricultura Familiar - PRONAF, que em 28 de julho de 1996 é institucionalizado com o Decreto Presidencial $n^{\circ} 1.946$, com suas linhas de crédito que impulsionou a agricultura de pequenos produtores.

Segundo a Secretaria Especial de Agricultura Familiar e do Desenvolvimento Agrário AFDA (2015):

A agricultura familiar mantém cerca de 12 milhões de pessoas economicamente ativas no campo, produzindo, gerando renda, interiorizando o desenvolvimento e alimentando os brasileiros. Segundo o diretor de Financiamento e Proteção à Produção da Secretaria da Agricultura Familiar do MDA, João Luiz Guadagnin, o PRONAF comemora 20 anos com indicadores de excelência. A inadimplência é menor que $1 \%$, o que demonstra que os agricultores familiares sabem gerenciar seus empreendimentos, produzir, comercializar, obter renda e honrar seus compromissos. 


\section{ISSN - 2447-178X}

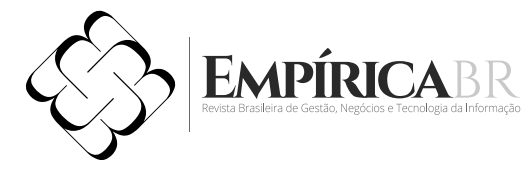

Essa permanência no campo é fator importante para os pequenos municípios, pois segundo AFDA (2015), "a agricultura familiar possui, portanto, importância econômica vinculada ao abastecimento do mercado interno e ao controle da inflação dos alimentos consumidos pelos brasileiros", sendo assim o presente estudo se justifica pela relevância da temática em face da situação atual de aplicação e desenvolvimento das políticas públicas na agricultura familiar nos pequenos municípios.

É certo que com incentivos é possível viabilizar o crescimento e a permanência do agricultor na sua terra, mas para isso é necessário questionar a atual situação, por esse motivo esse trabalho tem como objetivo principal, analisar os impactos da aplicação do PRONAF no assentamento Vingt Rosado Mossoró/RN na percepção dos agricultores familiares. E como objetivos adequados com a proposta: identificar as linhas de crédito aplicadas na comunidade; verificar as dificuldades de acesso ao PRONAF; e analisar a percepção dos agricultores familiares sobre o impacto do PRONAF no assentamento.

\section{REVISÃO BIBLIOGRÁFICA}

\subsection{Políticas Públicas no Brasil}

Todo o processo de construções de políticas públicas no Brasil se deu de maneira lenta. 0 país passou por grandes mudanças, da República Velha até o fim do Regime Militar para Republica Nova, época de grandes conflitos políticos e sociais, que foi responsável por estabelecer e construir a política brasileira. 0 Estado de fato só veio intervir de uma maneira mais expansiva, principalmente a região nordeste segundo Júnior 2012, isso aconteceu no final de 2002 ao início de 2003, nesse tempo ocorreu uma interferência mais intensificada nas políticas assistencialistas governamentais, que inferiram impactos maiores economicamente.

O termo política pública segundo Rua (2012, p. 17):

\footnotetext{
"referir-se à formulação de propostas, tomada de decisões e sua implementação por organizações públicas, tendo como foco temas que afetam a coletividade, mobilizando interesses e conflitos. Em outras palavras, policy significa a atividade do governo de desenvolver políticas públicas, a partir do processo da política".
}

Com a cogitação da interferência política como forma de organização, assume se assim a parcela que o Estado contraiu como provedor social, tentando de forma restrita nas suas limitações, seja do próprio jogo político ou financeiro, corrigir desvios sociais deixados por uma expansão rápida nesse período de mudanças no Brasil. 0 surgimento de políticas sociais voltadas para a sociedade, não se dispunha de força ou de interesse político. Alguns projetos começaram a vigorar, porém não tinha uma cobertura tão ampla na camada mais pobre da população, principalmente em regiões mais carentes do Brasil. Como por exemplo, de acordo com Júnior (2012), a criação do Programa de Assistência Rural (PRORURAL), que previa benefícios de aposentadoria e o aumento dos serviços de saúde aos trabalhadores rurais, e uma campanha de alfabetização de adultos, por meio do Movimento Brasileiro de Alfabetização (MOBRAL), durante o governo do ano de 1969. 


\subsection{Políticas públicas voltadas para agricultura familiar no Brasil}

Dentro da agricultura familiar as mudanças foram ainda mais difíceis, mesmo com a criação de políticas de investimentos nessa área, esses recursos eram destinados principalmente a grandes produtores agrícolas, que impulsiona o setor da agricultura com grandes volumes de produção e venda, tornando a competição do pequeno produtor insustentável.

De acordo com Müller, (2007, p. 14):

Entre os fatores que contribuíram de forma decisiva para a legitimação política e o reconhecimento social da importância da agricultura familiar na sociedade brasileira, está a elaboração de políticas públicas que têm como alvo privilegiado esta categoria social. Iniciadas na década de 1990, especialmente após a crise que leva ao impedimento do Governo Collor, as políticas públicas voltadas para a agricultura familiar passam a sofrer, lentamente, mudanças de enfoque em relação ao que se tinha até então, que eram ações de apoio à produção (crédito), estabilização de preços (PGPM), inovação científica e tecnologia (EMBRAPA) e assistência técnica (EMATER).

Os programas de financiamento que se dispunham na época, contavam com várias regras que dificultava o acesso a quem não tinha condições ou garantias de um retorno seguro do valor emprestado. Com vários fatores que impediam o acesso ao crédito, o desenvolvimento e a continuação e expansão da agricultura familiar, entrou em declínio, outras condições externas contribuíram, como fatores sociais, culturais econômicos, o que impulsionou a migração do homem do campo para a cidade.

Segundo Balsadi (2001, p. 3):

[...] para melhor entender o grande crescimento das ocupações rurais não-agrícolas da população economicamente ativa com domicílio rural, principalmente nos anos 80 e 90, é necessária a inclusão de outros fatores explicativos, os quais se relacionam com a crise na agricultura, com as novas funções do meio rural e a emergência de novos atores rurais, com as mudanças nas famílias rurais e nas explorações agropecuárias e com as similaridades entre os mercados de trabalho urbano e rural. Esses pontos, conjuntamente com o avanço tecnológico que reduz as ocupações agrícolas, ajudam a explicar, de forma mais adequada, por que cada vez mais a PEA rural nos diferentes países, desenvolvidos ou em desenvolvimento, ocupa-se fora das atividades agropecuárias.

Para reverter esse processo foi necessário rever a necessidade do pequeno agricultor, para possibilitar a sua permanência no campo, já que o meio urbano possibilitava condições à sobrevivência com ofertas de mão de obra. Foram então instituídos alguns programas com as ações de intervenção como a extensão dos direitos previdenciários aposentadorias rurais, Programa Nacional de Fortalecimento da Agricultura Familiar - PRONAF, o Programa Fome Zero - PFZ, programa de Aquisição de Alimentos - PAA e outros. 


\section{ISSN - 2447-178X}

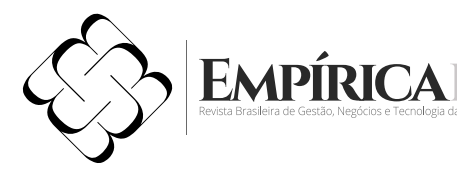

Uma concepção importante foi à criação do PRONAF a partir do decreto $N^{0} 1.946$, de 28 de junho de 1996, ele possibilitou uma junção através de convênio direto com pequenos agricultores, facilitando a possibilidade de crédito para o aumento da produção rural e consequentemente a melhoria da renda, porém o programa permitiu mais que isso, houve uma série de fatores associados, não apenas ao investimento na produção, mas também a visualização do lado social do próprio agricultor. Com a criação dessa política de investimento, foi possível o aprimoramento e investimentos em novas tecnologias, capacitação do próprio agricultor no seu meio rural, melhoramento de técnicas, adequação a novas tecnologias, capacitação e etc.

\subsection{Agricultura familiar na cidade de Mossoró/RN}

Mossoró está situada no interior do estado do Rio Grande do Norte, na região nordeste do Brasil. Pertence à mesorregião do Oeste Potiguar e à microrregião homônima. A cidade fica entre as capitais Natal e Fortaleza (CE), distante 278 e 245 km, respectivamente. (PREFEITURA MUNICIPAL DE MOSSORÓ, 2013).

De acordo com o Instituto Brasileiro de Geografia e Estatística - IBGE (2017), a área total do município é de 2.099,333 quilômetros quadrados, o que lhe dá o título de maior município do estado do Rio Grande do Norte, em termos de extensão territorial. O relevo é predominantemente plano, uma média de altitude de 100 metros. Sua formação é composta pela Depressão Sertaneja/São Francisco, pela Chapada do Apodi, por planícies fluviais e por depressões sublitorâneas. Nossa umidade relativa foi verificada em $70 \%$. Ainda segundo o relatório do IDEMA, pode-se encontrar no território mossoroense três tipos de vegetação distintos que são a caatinga hiperxerófila, o carnaubal e a vegetação halófica.

Com relação à utilização da terra, Mossoró conta com uma área de 3.233 ha para a cultura permanente, e de 7.193 há para utilização de cultura temporária, sendo que os principais grãos cultivados estão o feijão fradinho, que é produzido em 583 estabelecimentos agropecuários, incluindo os agricultores familiares, no total toda essa produção representa cerca de 922 t. Outro destaque é a produção de milho, que chega a ser produzido em 729 unidades, gerando 4.354 t (IBGE, 2006). Como a vegetação é escassa na maioria do ano, outra fonte de alimentação animal viável é o cultivo do sorgo para silagem, apesar do milho ainda representar fonte de mistura principal por possuir alto valor nutritivo, o cultivo do sorgo é mais barato sendo, portanto mais viável em épocas mais difíceis.

De acordo com o Instituto de Zootecnia - IZ (2004):

Seguindo o milho, vem a planta de sorgo, como a segunda mais adequada ao processo de ensilagem, mostrando composição química bastante semelhante à do milho. Existem no mercado basicamente três tipos de sorgo: granífero, de duplo propósito e forrageiro. Embora todos os tipos deem boas silagens, os de duplo propósito são os mais adequados ao processo. Tais sorgos são assim denominados porque atendem tanto a produção de grãos como a produção de forragem para ensilagem, mostram um 


\section{ISSN - 2447-178X}

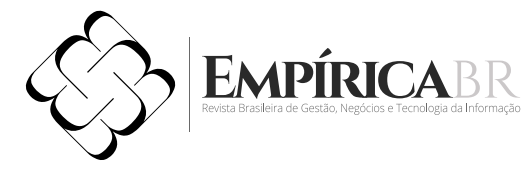

desenvolvimento intermediário entre os graníferos (de porte reduzido) e os forrageiros (de porte muito alto). O forrageiro por apresentar um porte muito alto, embora produza maior quantidade de matéria seca/ha, dá silagem de menor valor nutritivo que os de duplo propósito.

Assim logos nos primeiros períodos de chuva é possível fazer o preparo para o cultivo do sorgo, o mais utilizado é o de duplo propósito por apresentar condições melhores de cultivo e também por conter mais nutriente para os animais.

\subsection{O PRONAF e as linhas de acesso para os agricultores familiares}

A agricultura familiar tem papel relevante nos municípios brasileiros, ela é responsável por geração de renda de pequenos agricultores e abastecimento dos pequenos mercados desses municípios.

De acordo com MDA (2016):

Segundo dados do Censo Agropecuário de 2006, 84,4\% do total dos estabelecimentos agropecuários brasileiros pertencem a grupos familiares. São aproximadamente 4,4 milhões de estabelecimentos, sendo que a metade deles está na Região Nordeste [...] A agricultura familiar possui, portanto, importância econômica vinculada ao abastecimento do mercado interno e ao controle da inflação dos alimentos consumidos pelos brasileiros.

Incentivar os pequenos agricultores possibilita mais dignidade, sustentabilidade e desenvolvimento, não é apenas uma questão de estimulo ao homem do campo, trata do cultivo das suas raízes e da sua cultura no meio em que ele está inserido. Criar possibilidades econômicas para tal feito foi possível através de desenvolvimentos de programas.

Segundo o Banco Central do Brasil (2015):

\footnotetext{
Segundo o Banco Central do Brasil o PRONAF é programa Nacional de Fortalecimento da Agricultura Familiar (PRONAF) destina-se a estimular a geração de renda e a melhorar o uso da mão de obra familiar, por meio do financiamento de atividades e serviços rurais agropecuários e não agropecuários desenvolvidos em estabelecimento rural ou em áreas comunitárias próximas.
}

Para ter acesso ao programa é necessário seguir algumas regras estabelecidas pelo mesmo, a primeira é se enquadrar como beneficiário do programa, para isso é preciso obter a Declaração de Aptidão ao PRONAF - DAP, indo a um órgão emissor autorizado, como as empresas estaduais de Assistência Técnica e Extensão Rural, e os sindicatos rurais e de trabalhadores rurais, levando a carteira de identidade e o CPF. Com a DAP, o beneficiário, tem direito a acessar as políticas públicas do Governo Federal. 


\section{ISSN - 2447-178X \\ Segundo o MDA (2016):}

Com o documento, é possível ter acesso a mais de 15 políticas públicas, dentre elas o crédito rural do Programa Nacional de Fortalecimento da Agricultura Familiar (PRONAF); a Política Nacional de Assistência Técnica e Extensão Rural; e os programas de compras públicas, Programa de Aquisição de Alimentos (PAA) e Programa Nacional de Alimentação Escolar (PNAE). Atualmente, existem 4,8 milhões de DAPs ativas no Brasil.

Depois de conseguir a DAP, é possível identificar em qual categoria o beneficiário se encontra, deve-se observar em qual grupo o agricultor se enquadra, devendo-se resaltar os créditos oferecidos pelo programa, e suas respectivas finalidades, que de acordo com o Manual de Crédito Rural - MCR (2016):

1 - Os créditos podem ser destinados para custeio, investimento, industrialização ou integralização de cotas-partes pelos beneficiários nas cooperativas de produção agropecuária. (Res 4.575 art $3^{\circ}$ )

2 - Os créditos de custeio se destinam a financiar atividades agropecuárias e não agropecuárias de acordo com projetos específicos ou propostas de financiamento. (Res 4.575 art $3^{\circ}$ )

3 - Os créditos de investimento se destinam a financiar atividades agropecuárias ou não-agropecuárias, para implantação, ampliação ou modernização da estrutura de produção, beneficiamento, industrialização e de serviços, no estabelecimento rural ou em áreas comunitárias rurais próximas, de acordo com projetos específicos. (Res 4.107)

4 - Os créditos para integralização de cotas-partes se destinam a financiar a capitalização de cooperativas de produção agropecuárias formadas por beneficiários do Pronaf. (Res 4.107)

5 - Os créditos individuais, independentemente da classificação dos beneficiários a que se destinam, devem objetivar, sempre que possível, o desenvolvimento do estabelecimento rural como um todo. (Res 4.107)

6 - Os créditos de industrialização se destinam a financiar atividades agropecuárias, da produção própria ou de terceiros enquadrados no Pronaf, de acordo com projetos específicos ou propostas de financiamento. (Res 4.575 art $3^{\circ}$ ).

O custeio ou o investimento segue particularidades específicas, segundo a Confederação Nacional dos Trabalhadores Rurais, Agricultores e Agricultoras Familiares - CONTAG de acordo com o plano safra 2012/2013, se classifica da seguinte maneira. Segundo a Contag (2012), os créditos estão classificados 
de duas formas créditos de custeio e investimento mais alimentos. Nos créditos de custeio sua finalidade é custear as atividades agropecuárias ou não, sendo assim adquirido paras as seguintes finalidades, beneficiamento e industrialização da produção própria ou de terceiros enquadrados. Já na modalidade mais alimentos as características de financiamento volta se também para as atividades agropecuárias ou não, o destaque nesse caso é a questão de englobar também as atividades de serviços, que podem ser no estabelecimento rural ou em áreas comunitárias rurais próximas, variando sempre, dependendo do serviço ou projetos específicos.

Dentro da modalidade de crédito de custeio existem os financiamentos das linhas de crédito das atividades, agropecuárias ou não, com seus respectivos grupos específicos, no quadro 1 verifica-se com clareza essa divisão.

Quadro 1: Grupos e linhas de credito do PRONAF.

\begin{tabular}{|c|c|c|c|c|c|}
\hline $\begin{array}{l}\text { Grupos / } \\
\text { Linhas }\end{array}$ & Público-Ako & Finalidade & Limite de Crédito & Juros & $\begin{array}{c}\text { Prazo, Carência, Bônus de } \\
\text { Adimplência e Outras Condiçôes }\end{array}$ \\
\hline $\begin{array}{l}\text { Pronat } \\
\text { Grupo A }\end{array}$ & $\begin{array}{l}\text { Agrcultores/as) assentados/as) pelo } \\
\text { Programa Nacional de Reforna Agraria } \\
\text { (PNRA). } \\
\text { Beneficlarios do Programa Nacional de } \\
\text { Credto Fundiario (PNCF). }\end{array}$ & $\begin{array}{l}\text { Investimento em atividades } \\
\text { agropecuarias e nalo- } \\
\text { agropecuarias. }\end{array}$ & $\begin{array}{l}\text { Ate R\$ } 25.000,00 \text { por agricutor. } \\
\text { Esse valor podera ser elevado } \\
\text { para RS } 26.500,00 \text { quando } \\
\text { contemplar veroa para Assistencla } \\
\text { Tecnica. }\end{array}$ & $\begin{array}{c}0,5 \% \text { ao } \\
\text { ano. }\end{array}$ & $\begin{array}{l}\text { Prazo: ate } 10 \text { anos, Inciuldos ate } 3 \text { anos de carencla. } \\
\text { BOnus: } 43,396 \% \text { se houver assistencla tecnlca, ou de } \\
\text { 40\% quando esse serviço nắ for financlado. }\end{array}$ \\
\hline \multirow[b]{2}{*}{$\begin{array}{c}\text { Pronat } \\
\text { Grupo A/C }\end{array}$} & \multirow{2}{*}{$\begin{array}{l}\text { Agricultores/as) assentados/35) pelo } \\
\text { Proqrama Naclonal de Reforma Agraria } \\
\text { (PNRA). } \\
\text { Beneficlarios(as) do Proqrama Nacional } \\
\text { de Credto Fundlario (PNCF). }\end{array}$} & \multirow{2}{*}{$\begin{array}{l}\text { Custelo de attvidades } \\
\text { agropecuarlass e de } \\
\text { Denenclamento ou } \\
\text { industrializacto da } \\
\text { produçato. }\end{array}$} & \multirow{2}{*}{$\begin{array}{l}\text { Ate R5 } 7.500,00 \text { por operaç50, } \\
\text { podendo cada aqricultor contratar } \\
\text { ate } 3 \text { operaçles. }\end{array}$} & \multirow[b]{2}{*}{$\begin{array}{c}1,5 \% \text { ao } \\
\text { ano. }\end{array}$} & Custelo agricola: ate 2 anos. \\
\hline & & & & & Custelo pecuario e agroindustrial: ate 1 ano. \\
\hline $\begin{array}{l}\text { Pronat } \\
\text { Grupo B }\end{array}$ & $\begin{array}{l}\text { Agricultores(as) famillares com renda } \\
\text { bruta anual familiar de ate R5 20.000,00. } \\
\text { Mulheres agricutoras Integrantes de } \\
\text { unilades famillares enquadradas nos } \\
\text { Grupo A, AC e B do Pronat. }\end{array}$ & $\begin{array}{l}\text { Investlmentio em atividades } \\
\text { agropecuarias e nálo- } \\
\text { agropecuarias. } \\
\text { Custelo pecuario para } \\
\text { aquisiçato de animals } \\
\text { destinados a recria e } \\
\text { engorda. } \\
\text { Custelo de attividades náo } \\
\text { agropecuarias. }\end{array}$ & $\begin{array}{l}\text { R\$ } 5.000,00 \text { por operaçás } \\
\text { elaborada pela metodologla do } \\
\text { Agroamigo (PNMPO) } \\
\text { R\$ } 2.500,00 \text {, quando elaborada } \\
\text { sem a metodologla Agroamigo. }\end{array}$ & $\begin{array}{c}0,5 \% \text { ao } \\
\text { ano. }\end{array}$ & 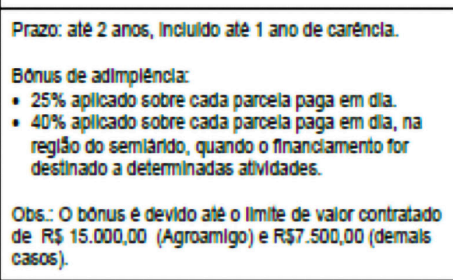 \\
\hline $\begin{array}{l}\text { Pronat } \\
\text { Mulher }\end{array}$ & $\begin{array}{l}\text { Mulheres agricuttoras, Independente do } \\
\text { estado civil, Integrantes de unidades } \\
\text { famillares enquadradas no Grupo V } \\
\text { (Renda Varlavel). } \\
\text { Obs,: as muheres integrantes dos } \\
\text { demals grupos serdo atendldass no } \\
\text { Pronaf Grupo B. }\end{array}$ & $\begin{array}{l}\text { Investimento da } \\
\text { Infraestrutura de produçálo e } \\
\text { servipos agropecuarios e } \\
\text { nálo agropecuatios no } \\
\text { estabelecimento rural, de } \\
\text { interesse da mulher } \\
\text { agricutora. }\end{array}$ & 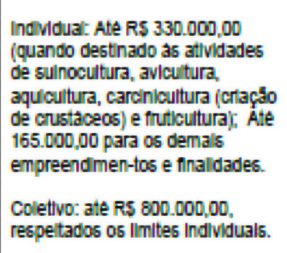 & $\begin{array}{c}2,5 \% \\
\text { ao ano } \\
\text { ou } \\
5,5 \% \text { ao } \\
\text { ano, } \\
\text { dependendo } \\
\text { da } \\
\text { destinaçato } \\
\text { do credito. }\end{array}$ & $\begin{array}{l}\text { Prazo: ate } 5 \text { anos para financlamentos de caminhonetes } \\
\text { de carga. } \\
\text { Prazo: ate } 10 \text { anos, Inciuldos ate } 3 \text { anos de carencia, } \\
\text { para as demals fnalldades. }\end{array}$ \\
\hline
\end{tabular}




\begin{tabular}{|c|c|c|c|c|c|}
\hline $\begin{array}{l}\text { Grupos e } \\
\text { Linhas }\end{array}$ & Público-Alvo & Finalidade & Limite de Crédito & Juros & $\begin{array}{c}\text { Prazo, Carência, Bônus de } \\
\text { Adimplência e Outras Condições }\end{array}$ \\
\hline $\begin{array}{c}\text { Pronat } \\
\text { Mals } \\
\text { Allmentos }\end{array}$ & $\begin{array}{l}\text { Agncuitores/as) famillares } \\
\text { enquadrados(as) no Grupo V (Renda } \\
\text { Varlavel) }\end{array}$ & $\begin{array}{l}\text { Investimento da } \\
\text { infraestrutura de produçaso e } \\
\text { servicos aqropecuarios e } \\
\text { nalo-agropecuartios no } \\
\text { estabelecimento rural }\end{array}$ & 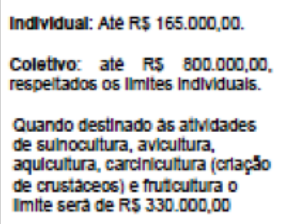 & $\begin{array}{c}2,5 \% \\
\text { ao ano } \\
\text { ou } \\
5,5 \% \text { ao } \\
\text { ano, } \\
\text { dependendo } \\
\text { da } \\
\text { destinaçato } \\
\text { do credto. }\end{array}$ & $\begin{array}{l}\text { Prazo: ate } 5 \text { anos para financiamentos de caminhonetes } \\
\text { de carga. } \\
\text { Prazo: ate } 10 \text { anos, Incluldos ate } 3 \text { anos de carencla, } \\
\text { para as demals finalldades. }\end{array}$ \\
\hline $\begin{array}{l}\text { Pronat Agro- } \\
\text { Industria }\end{array}$ & $\begin{array}{l}\text { Agricultores tamillares enquadrados nos } \\
\text { qrupos A A/C, Be Grupo V V Renda } \\
\text { Variavel) e suas cooperativas, } \\
\text { assoclaphes e empreendimentos } \\
\text { famillares rurats. }\end{array}$ & $\begin{array}{l}\text { Financliamento para a } \\
\text { implantacasto, ampilaço, } \\
\text { recuperaçao ou } \\
\text { modemizaç5o de pequenas } \\
\text { e medlas agroindustrias. }\end{array}$ & $\begin{array}{l}\text { Pessoa fislcax Rs } 165.000,00 \\
\text { Empreendimento famillar rurat: RS } \\
330.000,00 \\
\text { Coop LAssoc: } \text { RS } 35.000 .000,00 \text {. }\end{array}$ & $\begin{array}{l}5,5 \% \\
a 0 \text { ano }\end{array}$ & $\begin{array}{l}\text { Prazo: ate } 5 \text { anos, Inclulda a carencla de ate } 1 \text { ano, para } \\
\text { fnanclamentos de caminhonetes de carga; } \\
\text { Ate } 10 \text { anos, Incluidos ate } 3 \text { anos de carencla. }\end{array}$ \\
\hline $\begin{array}{l}\text { Pronat } \\
\text { Jovem }\end{array}$ & 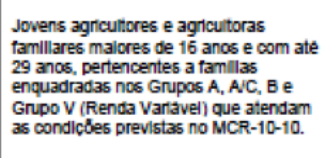 & $\begin{array}{l}\text { Financiamento da } \\
\text { Infraestrutura de producto e } \\
\text { serviços agropecuarios e } \\
\text { náp-aqropecuarios no } \\
\text { estabelecimento rural de } \\
\text { interesse do jovem } \\
\text { agricutor. }\end{array}$ & $\begin{array}{l}\text { Ate R5 } 16.500,00 \text {, em ate } 3 \\
\text { operaches. }\end{array}$ & $\begin{array}{c}2,5 \% \text { ao } \\
\text { ano. }\end{array}$ & Prazo: ate 10 anos, incluidos ate 3 anos de carencla. \\
\hline $\begin{array}{l}\text { Pronat } \\
\text { Induatriallza- } \\
\text { çao de } \\
\text { Aggroindus- } \\
\text { tria Famillar }\end{array}$ & $\begin{array}{l}\text { Agncultores familliares enquadrados nos } \\
\text { grupos A A AC, B e Grupo V (Renda } \\
\text { Variavel) e suas cooperativas, } \\
\text { associacoses e empreendimentos } \\
\text { famillares rurais. }\end{array}$ & $\begin{array}{l}\text { Financlamento do custelo do } \\
\text { benentiamento e } \\
\text { industrializaça de produçăo } \\
\text { propria e/ ou de terceiros. }\end{array}$ & $\begin{array}{l}\text { Pessoa fisica ate Rs } 12.000,00 \text {. } \\
\text { Empreendimento famillar nual: ate } \\
\text { Rs } 210.000,00 \text {. } \\
\text { Cooperativa singular. ate Rs } 10 \\
\text { milindes. } \\
\text { Cooperativa central: ate Rs } 30 \\
\text { milhdes. }\end{array}$ & $\begin{array}{c}5,5 \% \text { ao } \\
\text { ano. }\end{array}$ & Ate 12 meser. \\
\hline $\begin{array}{l}\text { Pronat } \\
\text { Semlarido }\end{array}$ & $\begin{array}{l}\text { Agncultores/as) famillares } \\
\text { encuadrados(as) nos Grupos A, AvC, B } \\
\text { e Grupo V (Renda Varavel). }\end{array}$ & $\begin{array}{l}\text { Investimento destlinado a } \\
\text { convivencla como o } \\
\text { semilanido, proitzando a } \\
\text { infraestrutura nidica. }\end{array}$ & Ate R5 $20.000,00$ & $\begin{array}{c}2,5 \% \text { ao } \\
\text { ano. }\end{array}$ & Prazo: ate 10 anos, Incluidos ate 3 anos de carencla. \\
\hline
\end{tabular}

\begin{tabular}{|c|c|c|c|c|c|}
\hline $\begin{array}{l}\text { Grupos e } \\
\text { Linhas }\end{array}$ & Público-Alvo & Finalidade & Limite de Crédito & Juros & $\begin{array}{c}\text { Prazo, Carência, Bônus de } \\
\text { Adimplência e Outras Condicôes }\end{array}$ \\
\hline \multirow{3}{*}{$\begin{array}{l}\text { Pronat } \\
\text { Custelo }\end{array}$} & \multirow{3}{*}{$\begin{array}{l}\text { Aqricultores/as) famillares } \\
\text { enquadrados(as) nos Grupos B e } \\
\text { Grupo V (Renda Varitave). }\end{array}$} & \multirow{3}{*}{$\begin{array}{l}\text { Custelo de attvidades } \\
\text { aqricolas e pecuarlas, } \\
\text { Incluslve aquiliçato de } \\
\text { animals para recila e } \\
\text { engorda. }\end{array}$} & \multirow{3}{*}{$\begin{array}{l}\text { Integrante do Grupo B do Pronat: } \\
\text { - Ate 4.000,00 pela metodologla } \\
\text { Aqroamlgo } \\
\text { - Ate R5 } 2.500,00 \text { quando fora da } \\
\text { metodoloqla. }\end{array}$} & $2,5 \%$ an ano & 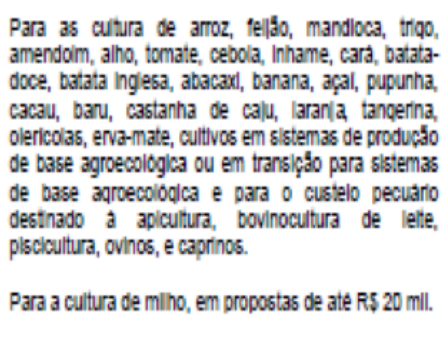 \\
\hline & & & & $5,5 \%$ an ano & $\begin{array}{l}\text { Para as demals ativiades, cultura de milho em } \\
\text { propostas acima de R5 } 20 \mathrm{ml} \text { e para aquislçalo de } \\
\text { animals destinados a recria e enquorda. }\end{array}$ \\
\hline & & & & & 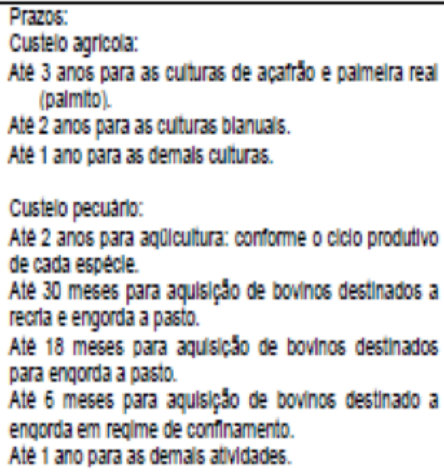 \\
\hline $\begin{array}{c}\text { Pronat } \\
\text { Agroecologla }\end{array}$ & $\begin{array}{l}\text { Agricultores fam llilares enquadrados nos } \\
\text { qrupos A, ACC, B e Grupo V (Renda } \\
\text { Varlavel). }\end{array}$ & $\begin{array}{l}\text { Investimento em sistemas } 35 \\
\text { de produç0 aqroecoloqicos } \\
\text { ou orquanicos. }\end{array}$ & $\begin{array}{l}\text { Indviduat: ate RS } 165.000,00 \\
\text { Colettvo: ate RS } 800.000,00 \text {. }\end{array}$ & $\begin{array}{l}2,5 \% \text { ao } \\
\text { ano. }\end{array}$ & Prazo: ate 10 anos, incluidos ate 3 anos de carencla. \\
\hline
\end{tabular}




\begin{tabular}{|c|c|c|c|c|c|}
\hline $\begin{array}{l}\text { Grupos e } \\
\text { Linhas }\end{array}$ & Público-Alvo & Finalidade & Limite de Crédito & Juros & $\begin{array}{c}\text { Prazo, Carência, Bônus de } \\
\text { Adimplência e Outras Condicôes }\end{array}$ \\
\hline $\begin{array}{l}\text { Pronaf } \\
\text { Floresta }\end{array}$ & $\begin{array}{l}\text { Agricultores tamillares enquadrados nos } \\
\text { grupos A, ACC, B e Grupo V (Renda } \\
\text { Varlavel). }\end{array}$ & 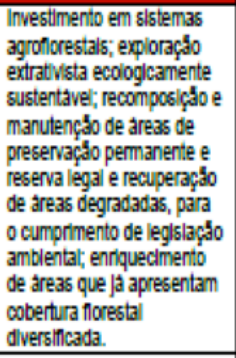 & $\begin{array}{l}\text { Agricultores do Grupo V ( Renda } \\
\text { Variavel): Ate Rs 35.000,00 } \\
\text { quando se destinar a sistemas } \\
\text { agroforestals; } \\
\text { Ate RS 27.500,00 para } 06 \text { demals } \\
\text { cas06. } \\
\text { Agricultores d06 Grupos A, ANC e } \\
\text { B. Ate RS15.000,00. }\end{array}$ & $\begin{array}{c}2,5 \% \text { ao } \\
\text { ano. }\end{array}$ & $\begin{array}{l}\text { Prazo: ate } 20 \text { anos, Incilda carencla limitada de ate } 12 \\
\text { anos, nos financlamentos com recursos do FNE, } \\
\text { destinados excusivamente para projetos de sistemas } \\
\text { agroficrestals, e ao publico-alvo do Grupo V (Renda } \\
\text { Varlave). } \\
\text { Prazo: ate } 12 \text { anos, Inculda a cartencla de ate } 8 \text { anos, } \\
\text { nos demals caso6. }\end{array}$ \\
\hline $\begin{array}{l}\text { Pronat } \\
\text { ECO }\end{array}$ & $\begin{array}{l}\text { Aaricultores tamillares enquadrados nos } \\
\text { grupos A, AC, B e Grppo V (Renda } \\
\text { Vartavel). }\end{array}$ & 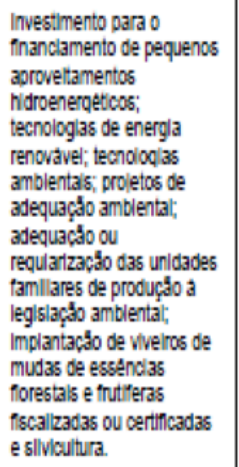 & 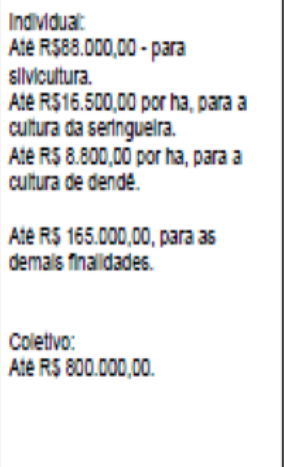 & $\begin{array}{l}5,5 \% \text { an ano } \\
\text { quando } 8 e \\
\text { tratar de } \\
\text { sllvicutura. } \\
2,5 \% \text { para } \\
\text { as dema's } \\
\text { finaldades. }\end{array}$ & $\begin{array}{l}\text { Prazo: ate } 16 \text { anos, Inciuldos ate } 8 \text { anos de carencla, } \\
\text { dependendo da fnalldade do credtio. }\end{array}$ \\
\hline $\begin{array}{l}\text { Pronaf } \\
\text { Microcredito } \\
\text { Produtlvo } \\
\text { Grupo A }\end{array}$ & $\begin{array}{l}\text { Agrcultores/as) assentados(as) pelo } \\
\text { Programa Nacional de Reforma Agraria } \\
\text { (PNRA), com renda bruta anual de ate } \\
\text { RS 20.000,00 eque nfo tenna contraldo } \\
\text { financiamento do Prona' Grupo A. }\end{array}$ & 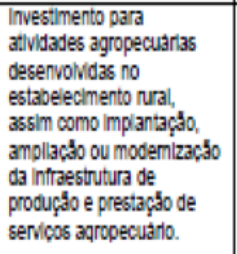 & $\begin{array}{l}\text { Ate R5 } 4.000,00 \text {, por ano aqricola. } \\
\text { Cada assentado podera fazer ate } \\
3 \text { operaçees. }\end{array}$ & $\begin{array}{c}0,5 \% \text { a } \\
\text { ano. }\end{array}$ & $\begin{array}{l}\text { Prazo: ate } 2 \text { anos. } \\
\text { Bonus de adimplencla: } 50 \% \text { soore cada prestaç50 de } \\
\text { divida paqa ate a data do seu respectivo vencimento. } 0 \\
\text { somatorio dos fnanclamentos concedldos com direlto a } \\
\text { bonus de adimplencla nato excederd R\$ } 12.000,00 \text {. }\end{array}$ \\
\hline
\end{tabular}

\begin{tabular}{|c|c|c|c|c|c|}
\hline $\begin{array}{l}\text { Grupose } \\
\text { Limhas }\end{array}$ & Público-Alvo & Fimalidade & Limite de Crélitio & Juros & $\begin{array}{l}\text { Prazo, Carêncin, Bônus de Adimplência e } \\
\text { Outras Condiçớes }\end{array}$ \\
\hline $\begin{array}{l}\text { Pronat } \\
\text { Produttvo } \\
\text { Orlantiso }\end{array}$ & 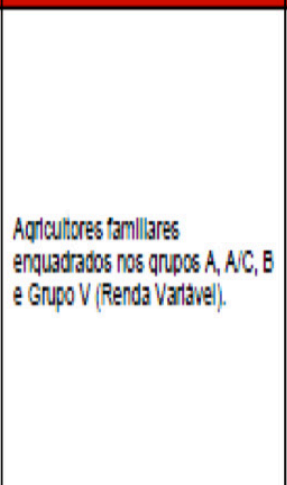 & 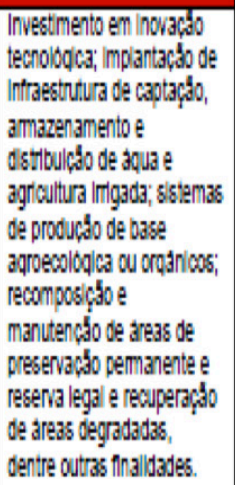 & 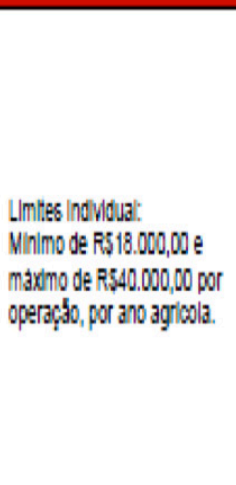 & $4,5 \%$ an ano. & 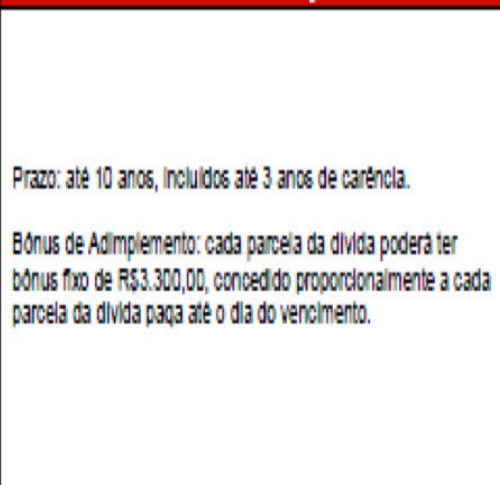 \\
\hline
\end{tabular}

Fonte: Banco do Nordeste (2017).

No quadro é possível observar que através do grupo em que o agricultor se encontra é possível identificar, por exemplo, o tipo de financiamento que pode ser acessado, a finalidade, os limites de crédito oferecidos, os juros, prazo de pagamento e etc. observando, porém que haverá pequenas variações de um banco para o outro. 


\section{METODOLOGIA}

As pesquisas consistem na realização de um estudo planejado com a finalidade de buscar respostas para um questionamento através do uso de métodos e técnicas científicas, por isso Marconi e Lakatos (2008) definem a pesquisa como um procedimento formal, com método de pensamento reflexivo, que requer um tratamento científico e se constitui no caminho para conhecer a realidade ou descobrir verdades parciais. Nessa direção, esta pesquisa foi desenvolvida a partir de um estudo de caso para esclarecer o problema proposto nesse trabalho, foi aplicado um formulário no assentamento Vingt Rosado localizado no município de Mossoró-RN, e o período de aplicação do mesmo foi compreendido no mês de agosto de 2017.

Quanto aos objetivos a pesquisa foi realizada utilizando o método descritivo. Segundo Gil (1994, p. 45), a pesquisa descritiva tem como principal objetivo "descrever características de determinada população ou fenômeno ou o estabelecimento de relações entre as variáveis, utilizando-se de técnicas padronizadas de coletas de dados".

Quanto aos procedimentos, esta pesquisa apresentou ser um estudo de caso, onde foram utilizadas, para a coleta dos dados, fontes primárias e secundárias. Como fonte primaria foi aplicado um formulário no assentamento Vingt Rosado em Mossoró/RN junto a trinta agricultores familiares do assentamento rural de um universo de oitenta e cinco famílias, bem como foram coletados dados de fonte secundária, através de livros, artigos, trabalhos publicados e sítios de pesquisa.

Para Gil (2010, p. 29) a pesquisa bibliográfica:

\footnotetext{
[...] é elaborada com base em material já publicado. Tradicionalmente, esta modalidade de pesquisa inclui material impresso, como livros, revistas, jornais, teses, dissertações e anais de eventos científicos. Todavia, em virtude da disseminação de novos formatos de informação, estas pesquisas passaram a incluir outros tipos de fontes, como discos, fitas magnéticas, CDs, bem como o material disponibilizado pela Internet.
}

O formulário aplicado foi do tipo estruturado, contendo 37 (trinta e sete) perguntas, entre elas abertas e fechadas. Segundo Prodanov e Freitas (2013) a elaboração do formulário também se trata de uma coleta de dados, pois ele organiza as perguntas em forma de questões onde o entrevistador faz as perguntas diretamente ao entrevistado, dessa forma o entrevistador tem o controle da situação podendo deixar mais claro a resposta obtida. A vantagem do formulário em relação a questionário, portanto é a relação "face a face" estabelecida durante a entrevista.

O formulário aplicado teve as seguintes abordagens: Identificar as linhas de crédito aplicadas na comunidade; verificar as dificuldades de acesso ao PRONAF; analisar a percepção dos agricultores familiares sobre o impacto do PRONAF no assentamento.

Quanto à abordagem do problema, foi aplicado um formulário do tipo estruturado, tratando se, portanto de uma pesquisa qualitativa e quantitativa. Segundo Prodanov e Freitas (2013), a pesquisa qualitativa não requer o uso de técnicas estatísticas e o ambiente natural é a fonte para a coleta de 
dados. Sendo uma pesquisa descritiva, os pesquisadores tendem a analisar seus dados indutivamente, tentando obter uma maior integração com o objeto de estudo. Já na pesquisa quantitativa se busca conhecer o comportamento dos indivíduos analisados.

Segundo Richardson et al. (2007, apud ZANELLA, 2012, p. 75):

\begin{abstract}
A pesquisa quantitativa é aquela que se caracteriza pelo emprego de instrumentos estatísticos, tanto na coleta como no tratamento dos dados, e que tem como finalidade medir relações entre as variáveis. Preocupa-se, portanto, com representatividade numérica, isto é, com a medição objetiva e a quantificação dos resultados.
\end{abstract}

Por fim, foi feita uma comparação entre as informações descritas no referencial teórico pesquisado e as respostas obtidas através do formulário aplicado aos agricultores do assentamento Vingt Rosado Mossoró RN, obtendo dessa forma, uma análise entre os resultados encontrados acerca do fenômeno estudado, na tentativa de elucidar a questão levantada acerca da problemática da pesquisa.

\title{
4 RESULTADOS E DISCUSSÕES
}

A pesquisa foi realizada no Assentamento Vingt Rosado no município de Mossoró/RN, sua localização tem em média de $24 \mathrm{~km}$ até a cidade de Mossoró, pólo a que pertence. De acordo com um entrevistado, "sua fundação se deu por meio agressivo, através de invasão e construção de barracos feitos com lonas, papelão e outros materiais diversos". Relatou ainda que "foi através de negociação com o INCRA, houve a constatação da necessidade das famílias que ali se encontravam", surgindo assim o assentamento Vingt Rosado, que tem uma área total de $1.580 \mathrm{~km}$, contando com cerca 85 famílias assentadas e mais 7 famílias agregadas, apresentando como característica o formato de agrovila. A divisão de lote é em torno de 10 hectares para cada família, e mais 2 a 3 hectares para cultivo ou criação. 0 assentamento ainda conta com área de preservação da mata nativa.

\subsection{Caracterizações gerais dos entrevistados}

Na primeira etapa foi realizada uma identificação das famílias assentadas, buscando a familiarização do cotidiano das mesmas, a elas foram feitas perguntas básicas, fechadas e abertas, buscando sempre deixar o entrevistado à vontade para se expressar. Todos os entrevistados responderam que se consideram agricultores familiares o que é uma situação típica dos assentamentos rurais brasileiros.

Nessa parte inicial o objetivo foi conhecer um pouco dos entrevistados, como nome, idade, escolaridade. Sobre a faixa etária dos mesmos, foi obtido como resposta que, cerca de $40 \%$ possui idade entre 40 e 50 anos, os outros $20 \%$, tem idade entre 20 e 31 anos, isso revela um contraponto bem interessante, que metade dos agricultores entrevistados, já está com cinqüenta anos ou entrando nessa faixa de idade.

Em relação à escolaridade, a maioria dos agricultores possui o ensino fundamental incompleto, cerca de $70 \%$, outros $10 \%$ tem ensino médio incompleto e $20 \%$ se enquadram como analfabetos 


\section{ISSN - 2447-178X}

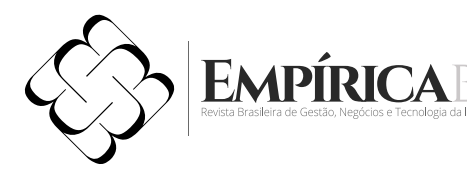

funcionais, sabendo ler e escrever o nome e decodificar as mensagens visuais do cotidiano.

Ainda foi questionado se algum membro da família deixou o assentamento para morar em outra cidade e se o mesmo tinha retornado. Apenas um dos entrevistados mencionou que "tenho uma filha, que devido aos estudos e casamento foi morar na cidade" (zona urbana).

Também foi perguntado o tempo em que esses assentados exercem a agricultura familiar. A maioria já nasceu dentro do ambiente rural, cerca de $70 \%$, ou foram introduzidos ao trabalho da agricultura familiar através da família. Em pesquisa realizada em municípios de Santa Catarina, segundo Silva (2016, p. 227): “É importante revelar que $80 \%$ dos agricultores possuem rendimentos unicamente de atividades agrícolas e daqueles que recebem outros rendimentos, metade deriva de aposentadorias do INSS". No geral o contato com o trabalho do cultivo agrícola faz parte da unidade familiar, representando o sustento.

\subsection{Linhas de crédito aplicadas no assentamento Vingt Rosado}

Esse tópico engloba as etapas 2 e 3 do questionário, levantando o questionamento a respeito da estrutura física e econômica, de modo geral, do assentamento. Foi constatado que o tipo de crédito utilizado pelos moradores compreende os grupos $\mathrm{A}$ e $\mathrm{A} / \mathrm{C}$, isso porque essas duas linhas de financiamentos são como uma espécie de passo inicial para os assentados, que representam três ciclos: Instalação, Inclusão Produtiva e Estruturação Produtiva, conforme as rotas de crédito.

Segundo o MDA (2016):

[...] o primeiro ciclo é voltado para a instalação do trabalhador rural na propriedade disponibilizada pelo governo. "A rota tem início com o Apoio Inicial I e II que é destinado à instalação e a aquisição de itens de uso doméstico. Esse recurso é de extrema importância, porque quando assentamos uma pessoa em um lote rural que só tem a terra e nenhuma benfeitoria ou casa, então a gente precisa dar uma estrutura mínima para que essas famílias possam viver ali".

A vida de quem vive da terra é muito difícil, principalmente conseguir um pedaço de chão. Assim, o PRONAF oferece aos assentados a oportunidade de uma vida digna para muitas famílias. Logo, as políticas públicas são extremamente importantes, pois infelizmente no Brasil não há a mesma igualdade para todos.

O segundo e terceiro passo representa a Inclusão Produtiva e a Estruturação Produtiva. Essa etapa merece atenção especial, pois é onde poderá notar o sucesso e desenvolvimento das famílias assentadas. Com isso surge à necessidade de acompanhamento contínuo das famílias pelos agentes que avaliam as implantações dos programas, nesse ponto surgem os financiamentos para infraestrutura e produção. Através da entrevista foi possível descobrir que os assentados solicitaram as linhas de crédito do PRONAF A, A/C e B, conforme os dados do quadro 2. 


\section{ISSN - 2447-178X}

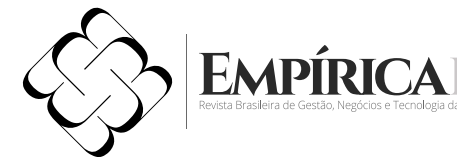

Quadro 2: Linhas de crédito aplicadas no assentamento Vingt Rosado

\begin{tabular}{|c|c|c|c|c|}
\hline Linhas de Crédito & $\begin{array}{l}\text { Quantidade de } \\
\text { Agricultures }\end{array}$ & Investimento & Custeio & Situação Atual \\
\hline PRONAF A & 30 & $\begin{array}{c}\text { Esse recurso foi } \\
\text { utilizado para a } \\
\text { construção das casas } \\
\text { dos moradores do } \\
\text { assentamento. }\end{array}$ & - & $\begin{array}{c}\text { As casas foram } \\
\text { construídas, e seus } \\
\text { prazos de pagamento } \\
\text { são estendidos, por } \\
\text { volta de } 10 \text { a } 30 \text { anos } \\
\text { para pagar. }\end{array}$ \\
\hline PRONAF A/C & 30 & - & $\begin{array}{l}\text { Esse custeio foi utilizado } \\
\text { para o melhoramento } \\
\text { de reforma de casas ou } \\
\text { estrutura da produção. }\end{array}$ & $\begin{array}{l}\text { Com esses valores } \\
\text { alguns moradores } \\
\text { fizeram alpendres } \\
\text { outros construíram } \\
\text { currais e etc. }\end{array}$ \\
\hline PRONAF B & 15 & - & $\begin{array}{l}\text { Esse custeio foi utilizado } \\
\text { para compra de animais, } \\
\text { especificamente } \\
\text { galinhas caipiras. }\end{array}$ & $\begin{array}{l}\text { Como esse recurso } \\
\text { não foi obtido êxito. }\end{array}$ \\
\hline
\end{tabular}

Fonte: Dados da pesquisa, 2017.

Como pode ser visualizado no quadro 2 , a linha de crédito do PRONAF A investimento, foi adquirido $100 \%$ pelos moradores do assentamento, esse tipo de investimento vem do Programa Nacional de Reforma Agrária PNRA e do Programa Nacional de Crédito Fundiário PNCF, essas aplicações fazem parte do ciclo inicial de instalação, pois esse fundo é destinado para a compra do imóvel, garantindo as famílias moradia.

Já o PRONAF A/C, que é para custeio de atividades agropecuárias e de beneficiamento ou industrialização da produção, foi contraído pelos moradores do assentamento representando um total de $100 \%$, e a maioria destinou o recurso para reformar as casas, já outros preferiram aplicar em estruturas, como construção de curral, entre outros. Esse recurso pode ser usado no melhoramento da infraestrutura de produção, estabelecimento rural ou em áreas comunitárias rurais. Silva (2016) aponta em suas pesquisas que a linha do PRONAF investimento foi considerada importante para os agricultores, isso porque esse crédito de investimento possibilitou adquirir máquinas e equipamentos além das reformas necessárias para as atividades.

As famílias assentadas também acessaram o PRONAF B, nesse caso o valor destinado foi acessado pelas mulheres agricultoras já enquadradas nas outras linhas de credito do PRONAF, nesse caso os grupos A e A/C. A linha de crédito do PRONAF B, segundo a figura 1, é um investimento em atividades pecuárias e não agropecuárias e custeio pecuário e de atividades não agropecuárias. No caso do assentamento foi utilizada para aquisição de animais destinados a recria e engorda em projetos de aquisição de galinhas caipiras, para um percentual de $50 \%$ dos assentados, porém não havendo muito êxito porque a escolha do animal não foi correta, porque a espécie que escolheram não obteve sucesso na reprodução, e nem adaptação ao clima, pois era necessária a criação de um local projetado para habituar-se à temperatura local.

A principal renda dos assentados vem do cultivo de milho, feijão e sorgo (esse último para alimentação animal), mas infelizmente só é possível o cultivo no período chuvoso, apesar de ter um 
poço artesiano no assentamento. É possível que com a perfuração de mais poços, o problema da falta de irrigação seja solucionado, durante os períodos de seca.

\subsection{0 programa do PRONAF e suas principais dificuldades de acesso}

Quando interrogados sobre a linha do PRONAF B investimento, muitos agricultores alegaram que a falta do acompanhamento contínuo do técnico, logo depois do período de implantação e consequentemente, dos primeiros meses da aquisição dos animais, contribuiu para o fracasso do projeto, pois o suporte e determinadas perguntas só poderiam ser sanadas através dos técnicos. Porém de acordo como a tabela do Banco do Brasil, os números dos contratos em relação à 2013/2017, no município de Mossoró RN, aumentaram significativamente, com isso não há garantias que o número de técnicos seja suficiente, para atender ao número de contratos solicitados pelos agricultores em geral.

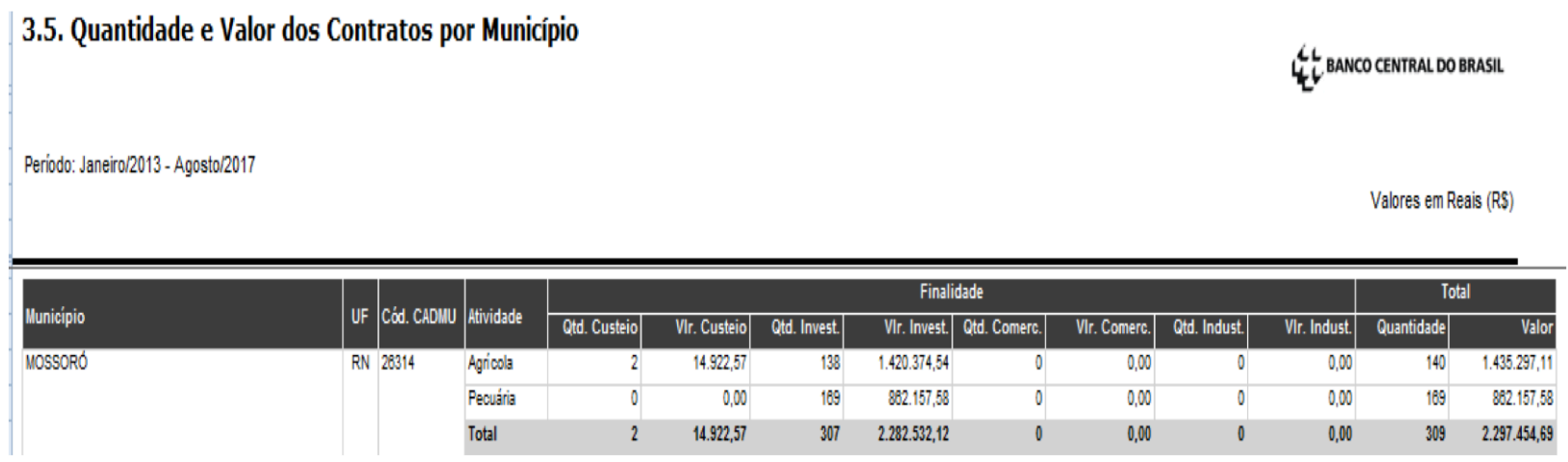

Figura 1: Quantidade e Valor dos Contratos por Município

Fonte: Banco Central do Brasil, 2017.

Portanto, percebe-se que mesmo com a assistência técnica sendo obrigatória dependendo do programa, do tempo de auxílio do técnico varia de acordo com a necessidade da aplicação do projeto em questão, que pode ser defino através de fases cabendo ao mesmo definir essa necessidade, portanto, se o agricultor achar que necessita de um prazo maior, além do estabelecido, será necessário a contratação com recursos próprios.

Outra dificuldade relatada em relação ao credito rural na categoria do PRONAF B é a necessidade de um avalista para ter acesso ao crédito perante o banco.

De acordo com o Banco Central (2015):

É necessária a apresentação de garantias para obtenção de financiamento do Pronaf [...] A escolha das garantias é de livre convenção entre o financiado e o financiador, que devem ajustá-las de acordo com a natureza e o prazo do crédito. No entanto, na concessão de crédito ao amparo das linhas especiais destinadas a agricultores familiares enquadrados nos Grupos «A», «A/C» $e$ «B» e das linhas Pronaf Floresta, Pronaf Semiárido e Pronaf Jovem de que tratam os itens do MCR 10-7, 10-8 e 1010, quando as operações forem realizadas com risco da União ou dos Fundos 


\section{ISSN - 2447-178X}

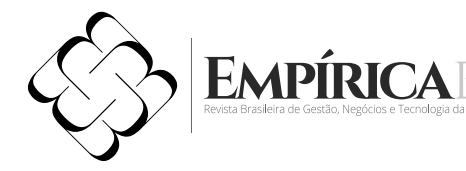

Constitucionais de Financiamento do Norte (FNO), do Nordeste (FNE) e do CentroOeste (FCO), deve ser exigida apenas a garantia pessoal do proponente, sendo admitido para estas operações o uso de contratos coletivos quando os agricultores manifestarem formalmente, por escrito, essa intenção.

O relatado foi que houve uma espécie de acordo entre os moradores do assentamento, "um ficou sendo avalista do outro". Mediante tal situação, temos o seguinte exemplo: dois produtores A e B, ambos são avalistas um do outro. Sendo A avalista de B, mesmo que o produtor $A$ pague a sua dívida, se $B$ não pagar, o produtor $A$ não poderá requerer um novo financiamento, pois seu nome ficará com pendências diante dos órgãos de crédito, impossibilitando o mesmo de participar de novos projetos, pois, o banco irá reavaliar a situação do agricultor e decidir se será liberado o crédito para financiamento, o que ocasionou certo conflito entre os moradores do assentamento, pois alguns agricultores, mesmo liquidando sua dívida, continuaram com o nome negativado.

Segundo Silva (2016, p. 216):

[...] duas observações podem ser feitas. A primeira referente alguns poucos agricultores que salientaram a contribuição positiva do que o programa proporcionou para retirar o nome dos órgãos de restrição ao crédito. A segunda referente ao agricultor que teve impacto inverso, ou seja, por ser avalista de outro agricultor foi incluído no Serasa.

Nesse caso não há impedimento na solicitação da DAP, a mesma não funciona como documento que comprova regularidade financeira, mas vale lembrar que a DAP é um dos documentos principais para que os agricultores tenham acesso às políticas públicas do Governo Federal.

\subsection{Análise e percepção dos agricultores familiares sobre o impacto do PRONAF no assentamento.}

Com relação aos impactos do PRONAF, de maneira geral, na vida dos agricultores do assentamento, constataram-se melhorias para as famílias instaladas no assentamento, pois tiveram a oportunidade de possuir lotes de terra para construir suas habitações, aumentar a renda familiar através da agricultura e criação de animais, aumento na produção agrícola, aquisição de bens para consumo. Porem ainda há certos receios em relação ao medo de endividamento e a dificuldade na solicitação de novos créditos. Segundo Silva (2016, p. 221): "consideradas com dificuldades [...] burocracia; dificuldade em entender e atender a legislação ambiental, e; medo de endividamento".

Porém, parte dos assentados alegou falhas no desenvolvimento e aplicação dos programas no que diz respeito ao acompanhamento de técnicos, burocracia em relação ao financiamento junto aos bancos (obrigatoriedade de apresentação de um avalista), valor dos recursos insuficientes para compra de animais e financiamento de máquinas.

De acordo com Guanziroli e Berenguer (2010, p. 50-51): 


\section{ISSN - 2447-178X}

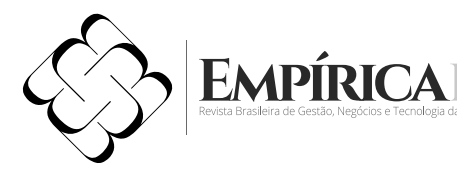

[...] O PRONAF converteu-se basicamente num sistema de crédito de custeio (curto prazo) com pouca ou nula assistência técnica e baixo nível de apoio para a infraestrutura, que era um dos eixos fundamentais, pela desestruturação que se verificava nos estabelecimentos familiares depois de décadas de total exclusão.

A partir dos programas do Governo Federal, de reforma agrária, investimento e do PRONAF foi possível à construção de moradia digna, bem como aquisição de eletrodomésticos, que por mais que este fato pareça simples para alguns, para outros se trata de uma realização. Um dos entrevistados relatou sentir se feliz em ir ao supermercado fazer sua feira, coisa que antigamente era fora de sua realidade, "era necessário escolher o que comprar o que tinha mais necessidade". Essa afirmação do agricultor familiar demonstra que o desenvolvimento de políticas públicas voltadas para agricultura familiar tende a melhorar a vida das famílias assentadas, proporcionando melhores condições de moradia, de alimentação e de inclusão social.

\section{CONCLUSÃO}

O objetivo desse trabalho foi analisar os impactos da aplicação do PRONAF no Assentamento Vingt Rosado Mossoró/RN, através da percepção dos agricultores familiares. Através da análise dos dados, buscou-se a interpretação dos resultados e, consequentemente, a formação de respostas para o problema proposto, permitindo assim a verificação do funcionamento do programa do PRONAF.

No primeiro objetivo o intuito foi identificar as linhas de credito do PRONAF aplicadas aos agricultores do assentamento, com o estudo foi observado que eles utilizaram de inicio como partes das três etapas, utilizadas para acolhimento das famílias oriundas de reforma agrária, a linha do PRONAF A, e as demais $A / C$ e B. Essas linhas de crédito servem como ajuda inicial, pois nesse primeiro momento os assentados não possuem nem capacidade financeira para construir as suas moradias. No PRONAF A os recursos foram destinados para construção da casa, o PRONAF A/C, para investir na compra de máquinas como, por exemplo, plantadeira, trator de uso comunitário e etc. Já a linha de crédito B é um recurso destinado na aquisição de animais, que no caso do assentamento foi à compra de galinhas. Então o que se conclui, é que de fato foram aplicados recursos do PRONAF no assentamento, porém o êxito nos seus resultados não foi satisfatório.

O segundo objetivo era verificar as dificuldades de acesso ao PRONAF, foi relatado pelos moradores do assentamento, a burocracia dos bancos na liberação dos recursos e falta de assistência técnica, esses foram os fatores que mais pesaram. 0 crédito rural na categoria do PRONAF B, exige um avalista, sendo necessária à apresentação de garantias para obtenção de financiamento do PRONAF. Isso se deve a insegurança dos bancos devido à crise financeira, que afetou diretamente os setores econômicos incidindo através das altas taxas de juros, no período de 2015/2016. Já a questão dos técnicos se trata de um problema bem mais profundo, porque a maioria dos programas requer um laudo e acompanhamento dos mesmos, porém como foi observada, essa assistência sofre influência 


\section{ISSN - 2447-178X}

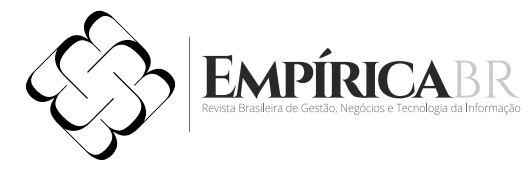

de diversos fatores, como por exemplo, do próprio programa em que o técnico está vinculado, e dependendo desse programa, essa assistência técnica será de longo ou curto prazo. 0 ideal é que com o número de aumento de contratos, fossem disponibilizados mais técnicos para atender a demanda, e que esse período de auxílio do técnico, ultrapasse a meta estabelecida posterior da implantação do programa.

No último tópico o intuito foi analisar a percepção dos agricultores familiares sobre o impacto do PRONAF no assentamento, nesse aspecto temos duas perspectivas positivas em relação à obtenção de moradia e trabalho. Dessa forma as linhas de créditos do PRONAF do Governo Federal possibilitou qualidade de vida, para 85 famílias assentadas e mais 7 agregadas do assentamento Vingt Rosado e muitos outros agricultores familiares do Brasil. Portanto para as famílias assentadas, o PRONAF gerou um impacto positivo no assentamento.

Na região Nordeste o clima é extremamente seco a maior parte do ano, e tirar o sustento apenas da agricultura representa uma luta diária, chegando a ser quase impossível. Daí a necessidade contínua de auxilio por parte do Governo, porque as três primeiras fases de adaptação das famílias no assentamento são fáceis, injetar recursos e acomodar as famílias, não se torna de fato um trabalho finalizado, o acompanhamento pós as três fases no ponto de vista geral, é fundamental, pois garantir a continuidade dos programas, seja a criação de animais ou cultivo agrícola, torna se fator decisivo para que a família no ambiente agrário não saia novamente do campo para a cidade na busca de emprego.

Através das entrevistas com os agricultores do Assentamento Vignt Rosado, foi possível notar o excelente potencial de desenvolvimento em relação aos fatores de recursos humanos e físicos, mas não houve a obtenção de êxito, porque na verdade são vários os elementos que influenciam na obtenção de resultados, é como se cada segmento tivesse sua parcela de culpa.

No estado atual o assentamento encontra-se estagnado, mesmo com os programas de auxílio do Governo. É necessário fazer uma investigação mais aprofundada do assentamento Vingt Rosado, haja vista que, há um leque de fatores que interferem no melhoramento da qualidade de vida e, portanto no desenvolvimento do assentamento, como burocracias bancárias, conflitos interno entre os moradores, assistência técnica insuficiente, que na maioria dos casos, é devido à própria condição do recurso solicitado e etc.

Se forem analisados os mesmos fatores pesquisados nesse trabalho e aplicar em outros assentamentos, possivelmente podem-se constatar situações semelhantes, haja vista, que no aspecto financeiro a forma de aplicação dos recursos é a mesma, no lado social as etapas de inclusão das famílias oriundas da reforma agrária seguem padrões parecidos e são utilizados os mesmos recursos inicialmente nesse tipo de programa destinado para as famílias assentadas. Sendo assim seria interessante testar essa suposição para saber quais outros fatores podem influenciar o desempenho na obtenção de êxito na aplicação dos programas do PRONAF no assentamento, e avaliar se os mesmos problemas são constatados.

Portanto avaliando dessa forma, seria interessante ter como base estudos que demonstre através de fatores padronizados, e que tenham sido aplicados em outras localidades (que podem ser assentamentos ou não), isso serviria de base para implantação de novos projetos, e também ajudaria 


\section{ISSN - 2447-178X}

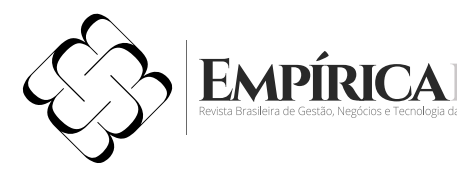

a minimizar os impactos negativos na busca de êxito para os novos programas. Pois com resultados de estudos realizados em assentamentos em fase de andamento ou conclusão de sua implantação, será possível fazer uma análise dos erros e acertos, obtendo assim dados relevantes na hora de aplicar os recursos do governo, e de alocar pessoas (famílias) para novos assentamentos. Dessa forma esse trabalho serve inicialmente de alerta, na busca para contribuir e agregar resultados para novas pesquisas com este tema.

\section{REFERÊNCIAS}

1. CARNEIRO, Maria José. Política pública e agricultura familiar: uma leitura do Pronaf. Disponível em: <http://r1.ufrrj.br/esa/V2/ojs/index.php/esa/article/view/106 > Acesso em: 26 mai. 2017.

2. CONTAG. Os créditos do PRONAF podem destinar-se a custeios ou investimentos. Disponível em: < http://www.contag.org.br/indexdet2. php?modulo=portal\&acao=interna2\&codpag=301\&ap=1\&nw=1\&ap=1>. Acesso em: 16 set. 2017.

3. BRASIL. Secretaria Especial de Agricultura Familiar e do Desenvolvimento Agrário (AFDA). 24 de agosto 2015. Disponível em:< http://www.mda.gov.br/sitemda/noticias/pronaf-20-anos-de-apoioaos-agricultores-familiares>. Acesso em: 28 mai. 2017.

4. Decreto No 1.946, de 28 de junho de 1996. Cria o Programa Nacional de Fortalecimento da Agricultura Familiar - PRONAF, e dá outras providências. Revogado pelo decreto 3992, de 30.10.2001. Brasília, 28 de junho de 1996; $175^{\circ}$ da Independência e $108^{\circ}$ da República. Disponível em:< http://www. planalto.gov.br/ccivil_03/decreto/d1946.htm >. Acesso em: 28 mai. 2017.

5. Decreto $\mathrm{N}^{\circ}$ 58.380, de 10 de maio de 1966. Aprova o Regulamento da Lei que Institucionaliza o Credito Rural. Brasília, 10 de maio de 1966; $145^{\circ}$ da Independência e $78^{\circ}$ da República. Disponível em:<http://www.planalto.gov.br/ccivil_03/decreto/antigos/d58380.htm>. Acesso em: 28 mai. 2017.

6. Lei $n^{\circ} 4.829$ de 05 de Novembro de 1965. Que dispõe sobre a institucionalização do crédito rural. Brasília, 05 de novembro de 1965; $144^{\circ}$ da Independência e $77^{\circ}$ da República. Disponível em: < http://www.planalto.gov.br/ccivil_03/leis/L4829.htm >. Acesso em: 26 mai. 2017.

7. Ministério da Agricultura MDA. 0 que é a agricultura familiar 2016. Disponível em: <http:// www.mda.gov.br/sitemda/noticias/o-que-\%C3\%A9-agricultura-familiar>. Acesso em: 16 set. 2017.

8. Ministério da Agricultura MDA. Rota de crédito viabiliza estruturação dos assentados da reforma agrária. Disponível em: <http://www.mda.gov.br/sitemda/noticias/rota-de-cr\%C3\%A9ditoviabiliza-estrutura\%C3\%A7\%C3\%A3o-dos-assentados-da-reforma-agr\%C3\%A1ria>. Acesso em: 23 set. 2017. 
Ministério da Agricultura MDA. Saiba como obter a declaração de aptidão ao PRONAF (DAP). Disponível em: <ttp://www.mda.gov.br/sitemda/noticias/saiba-como-obterdeclara\%C3\%A7\%C3\%A3o-de-aptid\%C3\%A3o-ao-pronaf-dap>. Acesso em: 16 set. 2017.

10. BANCO CENTRAL DO BRASIL BACEN. Programa Nacional de Fortalecimento da Agricultura Familiar - Pronaf. Disponível em: <https://www.bcb.gov.br/pre/bc_atende/port/PRONAF.asp\#1>. Acesso em: 16 set. 2017.

11. BANCO CENTRAL DO BRASIL BACEN. Manual de Credito Rural MCR. Programa Nacional de Fortalecimento da Agricultura Familiar (Pronaf)- Finalidades dos Créditos. Disponível em:< http://www3. bcb.gov.br/mcr>. Acesso em: 16 set. 2017.

12. BANCO CENTRAL DO BRASIL BACEN. FAQ - Programa Nacional de Fortalecimento da Agricultura Familiar - Pronaf 2015. Disponível em:<https://www.bcb.gov.br/pre/bc_atende/port/PRONAF.asp>. Acesso em: 25 mai. 2017.

13. BANCO DO NORDESTE. Grupos e Linhas de Credito PRONAF-Quadro resumo. Disponível em:<https://www.bnb.gov.br/documents/165130/231210/tabela_dos_grupos_Julho_2017/ebfbf37475ab-0dd9-3ca2-60e08a1e91dc>. Acesso em:22 set. 2017.

14. BANCO CENTRAL DO BRASIL BACEN.Quantidade e Valor dos Contratos por Município.Disponívelem:<http://www.bcb.gov.br/ptbr/\#!/r/ micrrural/ ? path = conteudo\% 2 FMDCR\%2FReports\%2FqvcMunicipio. rdI \& nome $=Q$ uantidade $\% 20$ e $\% 20$ Valor $\% 20$ dos $\% 20$ Contratos \% 20 por $\% 20$ Munic\%C3\%ADpio\&exibeparametros=true\&botoesExportar=true>. Acesso em:23 set. 2017.

15. BALSADI, Otavio Valentim. Mudanças no meio rural e desafios para o desenvolvimento sustentável. São Paulo Perspec. vol. 15 no. 1 São Paulo SP. Jan./Mar. 2001. Disponível em: <http:// www.scielo.br/pdf/spp/v15n1/8599.pdf>. Acesso em: 27 mai. 2017.

16. GUANZIROLI, Carlos Enrique; BUAINAIN, Antonio Marcio; SABBATO Alberto Di. Dez anos de evolução da agricultura familiar no Brasil: (1996 e 2006). Revista de Economia e Sociologia Rural, Piracicaba, Vol. 50, N² 2, p. 351-370, Abr/Jun. 2012. Disponível em: <http://www.scielo.br/scielo. php?pid=S0103-20032012000200009\&script=sci_arttext\#1a>. Acesso em: 26 mai. 2017.

17. GUANZIROLI, Carlos; BERENGUE, Marco Ortega. Experiências recentes bem-sucedidas no Brasil em agronegócio e desenvolvimento rural sustentável. Brasília: IICA, 2010. Disponível em:< http://www. iicabr.iica.org.br/wp-content/uploads/2014/03/experiencias_recentes.pdf>. Acesso em: 24 set. 2017.

18. GIL, Antonio Carlos. Como elaborar projetos de pesquisa. 5a ed. São Paulo: Atlas, 2010. 184 p.

19. INSTITUTO BRASILEIRO DE GEOGRAFIA E ESTATÍSTICA (IBGE). Infograficos - I nformações completas. Disponível em: <https://cidades.ibge.gov.br/xtras/perfil.php?lang=\&codmun=240800\&sear ch=rio-grande-do-norte|mossoro|infograficos:-informacoes-completas>. Acesso em: 21 ago. 2017. 


\section{ISSN - 2447-178X}

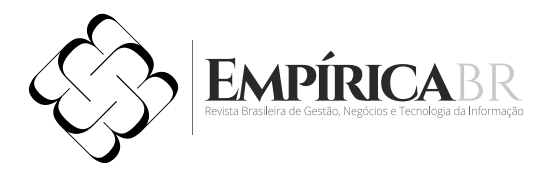

20. INSTITUTO BRASILEIRO DE GEOGRAFIA E ESTATístiCA (IBGE). Censo agropecuário 2006. Disponívelem:<http://https://cidades.ibge.gov.br/xtras/temas.php?lang=\&codmun=240800\&idtema=3 \&search=rio-grande-do-norte|mossoro|censo-agropecuario-2006>. Acesso em: 21 ago. 2017.

21. INSTITUTO DE ZOOTECNIA IZ. Plantas utilizadas para produção de silagem 2004. Disponível em:<http://www.iz.sp.gov.br/noticia.php?id=155>. Acesso em: 22 ago. 2017.

22. JÚNIOR, Alcides Domingues Leite. Desenvolvimento e mudanças no estado brasileiro. 2. ed. reimp. - Florianópolis: Departamento de Ciências da Administração / UFSC, 2012. 88p. : il.

23. KAUARK, Fabiana da Silva; MALHÃES, Fernanda Castro; MEDEIROS, Carlos Henrique. Metodologia de Pesquisa: um guia prático.Bahia: Via Litterarum, 2010. Disponível em: < http://www. pgcl.uenf.br/2014/download/LivrodeMetodologiadaPesquisa2014.pdf> Acesso em 26 jun. 2017.

24. LAKATOS, Eva Maria; MARCONI, Marina de Andrade. Técnicas de Pesquisa: Planejamento e Execução de Pesquisas, Amostragens e Técnicas de Pesquisa. 7 ed. São Carlos: Scipione, 2008.

25. MÜLLER. Ana Luiza. A construção das políticas públicas para a agricultura familiar no Brasil: o caso do Programa de Aquisição de Alimentos / Ana Luiza Müller. - Porto Alegre, 2007. 128 f.: il.

26. PREFEITURA MUNICIPAL DE MOSSORÓ (PMM). Geografia. Disponível em: < http://www. prefeiturademossoro.com.br/mossoro/geografia/>. Acesso em: 21 de ago. 2017

27. PRADANOV, Cleber Cristiano; FREITAS, Ernani César. Metodologia do Trabalho Científico: Métodos e Técnicas de Pesquisa e do Trabalho Acadêmico. 2 ed. Rio Grande do Sul: Freevale, 2013. Disponível em: < http://www.feevale.br/Comum/midias/8807f05a-14d0-4d5b-b1ad-1538f3aef538/Ebook\%20Metodologia\%20do\%20Trabalho\%20Cientifico.pdf> Acesso em 26 jun. 2017.

28. RUA, Maria das Graças. Políticas públicas. 2. ed. reimp. Florianópolis: Departamento de Ciências da Administração / UFSC, 2012. 128 p. : il.

29. SILVA, Roniel Antonio da. Impactos do PRONAF em Municípios Selecionados de Santa Catarina. Florianópolis, SC, 2016. 267 p.

30. ZANELLA, Liane Carly Hermes. Metodologia de estudo e de pesquisa em administração. 2. ed. reimp. Florianópolis: Departamento de Ciências da Administração / UFSC, 2012. 160p. : il. 